\title{
Immunomodulatory Activity of the Newly Synthesized Compound TOK-8801 (N-(2-Phenylethyl)-3,6,6-Trimethyl- 5,6-Dihydroimidazo[2,1-b]thiazole-2-Carboxamide)
}

\author{
Masami FUJIWARA, Kensuke SHIBATA, Noriyasu TAKAYANAG| ${ }^{1}$, \\ Kenji MATSUNARI ${ }^{2}$ and Itaru YAMAMOTO* \\ Department of Immunochemistry, Faculty of Pharmaceutical Sciences, \\ Okayama University. Okayama 700. Japan \\ 'Medicinal Research Laboratories, Toyo Jozo Co., Ltd., Shizuoka 410-23, Japan \\ ${ }^{2}$ Research and Development Department, Kumiai Chemical Industry Co., Ltd., \\ Tokyo 110. Japan
}

Accepted September 2, 1989

\begin{abstract}
The in vitro and in vivo effects of the newly synthesized compound TOK-8801 ( $\mathrm{N}$-(2-phenylethyl)-3,6,6-trimethyl-5,6-dihydroimidazo[2,1-b] thiazole2 -carboxamide) on immune responses were investigated in comparison with that of levamisole (LMS). TOK-8801 enhanced the anti-sheep red blood cells (SRBC) plaque forming cells (PFC) response and mitogen-induced proliferative responses in murine splenocytes and thymocytes in vitro at concentrations of $10^{-7}-10^{-5} \mathrm{M}$, while LMS augmented these responses at $10^{-4} \mathrm{M}$. The stimulatory effect of TOK-8801 as well as LMS on the antibody production was eliminated by the removal of T cells. TOK-8801 $(0.5 \mathrm{mg} / \mathrm{kg}$, p.o.) suppressed the in vivo generation of anti-SRBC PFC in normal mice, but the compound restored the depressed antibody production in restraint-stress mice which was mainly caused by helper $T$ cell defects. From these results, TOK-8801 was shown to have an immunomodulatory activity in the antibody production.
\end{abstract}

The immune system is diversely controlled by the interaction of subsets of lymphocytes such as $T$ lymphocytes, B lymphocytes, macropharges and granulocytes. The inbalance of these immune networks is associated with the pathogenesis of autoimmune disease. of which the representative is rheumatoid arthritis (RA). Since Jaffé used $D$-penicillamine for the treatment of RA in 1964 (1). several immunomodulating agents have been introduced at different clinical stages to improve the immune dysfunction. The therapeutic use of levamisole (LMS), which was originally designed as an anthelmintic, as an anti-rheumatic drug was first reported by Schuermans in 1975 (2). The immunopharmacological profile and the clinical application of LMS were well-

\footnotetext{
* To whom correspondence should be addressed.
}

investigated as described by Symoens and Rosenthal (3). However, these drugs produced serious side effects during the treatment of disease. We have synthesized hundreds of imidazothiazole compounds and selected TOK-8801 ( $\mathrm{N}$-(2-phenylethyl)3.6.6 - trimethyl - 5,6 - dihydroimidazo[2.1 - b] thiazole-2-carboxamide) as an immunomodulator (Fig. 1), given that it has an in vitro immunostimulatory activity at lower concentrations than other derivatives and less toxicity. This is the first report evaluating the effects of TOK-8801 on the in vitro and in vivo immune responses.<smiles>CC1=C(C(=O)NCCc2ccccc2)SC2=NC(C)(C)CN21</smiles>

Fig. 1. Chemical structure of TOK-8801. 


\section{Materials and Methods}

Animals: Female BALB/c mice (7-9 w.) for the in vitro study and male BDFI mice $(6-8 w$.) for the in vivo study were purchased from Charles River Japan, Inc.

Materials: TOK-8801 was synthesized by Kumiai Chemical Industry Co., Ltd., Japan: and LMS was purchased from Sigma, U.S.A. Other materials were obtained from the following sources: fetal calf serum (FCS) (GIBCO, U.S.A.), sheep red blood cells (SRBC) (Nishinippon Sheep Pharm, Japan). concanavalin A (Con A) (Sigma, U.S.A.). lipopolysaccharicies of E. coli 055B5 (LPS) (Difco. US.A.), monoclonal anti-Thy 1.2 antibody (Serotec, U.S.A.), guinea pig complement (Kyokuto Seivaku, Japan), and [6- $\left.{ }^{3} \mathrm{H}\right]$ thymidine $\left({ }^{3} \mathrm{H}\right.$-TdR) (Amersham. Japan). RPMI-1640 medium (Flow Laboratories, Scotland) was usually supplemented with penicillin $G$ potassium $(100 \mathrm{U} / \mathrm{ml}$; Banyu Pharmaceutical Co., Ltd., Japan) and streptomycin sulfate $(100 \mathrm{\mu g} / \mathrm{ml}$; Meiji Seika Co., Ltd., Japan). Trinitrophenyl (TNP)LPS was prepared by the procedure described by Rittenberg and Amkraut (4).

In vitro antibody production: Spleen cells $\left(8 \times 10^{6}\right)$ from BALB/c mice were cultured with SRBC $\left(2 \times 10^{6}\right)$ or TNP-LPS $(1 / \mu \mathrm{g} / \mathrm{ml})$ in $1.5 \mathrm{ml}$ of RPMI-1640 medium containing $10 \%$ FCS using multidishes with 24 wells (NUNC) for 5 days at $37^{\circ} \mathrm{C}$ under $5 \% \mathrm{CO}_{2}-$ $95 \%$ air. The compound to be tested for its effect on this response was added at the initiation of the culture. The number of antiSRBC plaque-forming cells (PFC) was enumerated by the method of Jerne and Nordin (5). Anti-TNP PFC was detected using TNP-conjugated SRBC (6). In some experiments, $T$ cells were removed from spleen cells by the treatment with anti-Thy 1.2 antibody for $30 \mathrm{~min}$ at $4{ }^{\circ} \mathrm{C}$ and with guinea pig complement for another $30 \mathrm{~min}$ at $37^{\circ} \mathrm{C}$. The depletion of $\mathrm{T}$ cells was confirmed by the evidence that anti-SRBC PFC were not present in the culture of anti-Thy 1.2 treated spleen cells. To reconstitute the antiSRBC PFC response of T cell-depleted spleen cells, Con A-supernatant (CAS, see below) was added as a T cell replacing factor (TRF). at a final volume of $20 \%(\mathrm{v} / \mathrm{V})$, to achieve a comparable response to that of spleen cells treated with complement only.

Preparation of CAS: CAS was prepared as follows: BALB/C mouse spleen cells $\left(5 \times 10^{6}\right.$ / $\mathrm{ml})$ were cultured with Con $A(5 \mu \mathrm{g} / \mathrm{ml})$ in the presence of 2-mercaptoethanol (2-ME, $5 \times 10^{-5} \mathrm{M}$; Nacalai Tesque, Japan) in RPMI1640 medium containing $10 \%$ FCS. After 24 $h r$, the supernatant was collected, dialyzed against PBS to remove $2-M E$, and added $\alpha$ methyl-D-mannoside ( $\alpha$-MM. $10 \mathrm{mg} / \mathrm{ml}$; Sigma, U.S.A.) to neutralize residual Con $A$ activity. This preparation was stored at $-70^{\circ} \mathrm{C}$ until use.

In vitro mitogen-induced proliferative response: Spleen cells $\left(2 \times 10^{5}\right)$ or thymus cells $\left(2 \times 10^{5}\right)$ from BALB/C mice were cultured with Con A (1 or $5 \mu \mathrm{g} / \mathrm{ml})$ or LPS $(10 \mu \mathrm{g} / \mathrm{ml})$ in $0.2 \mathrm{ml}$ of RPMl-1640 medium containing $5 \%$ FCS using round-bottomed microculture plates with 96 wells (NUNC) for 2 days and were pulsed with $0.5 \mu \mathrm{Ci}$ of ${ }^{3} \mathrm{H}-\mathrm{TdR}$ for an additional $18 \mathrm{hr}$. Then, cells were harvested on glass fiber fillters, and ${ }^{3} \mathrm{H}-\mathrm{TdR}$ incorporation was measured in a liquid scintillation counter. The compounds to be tested were added at the initiation of the culture.

In vivo antibody production in stressed or non-stressed mice: Stress loading was conducted as described by Okimura and Yamamoto (7) with some modifications; i.e.. BDF mice were fixed in restraint cages for $12 \mathrm{hr}$ per day (9:00 to 12:00) for 2 days. Control mice were maintained without food or water while counterparts were under the condition of restraint-stress. On the next day, the mice were immunized with $5 \times 10^{8}$ SRBC intraperitoneally. Immediately, $24 \mathrm{hr}$ and $48 \mathrm{hr}$ after the immunization. TOK-8801 dissolved in distilled water was orally given at doses of $0.02,0.1$ and $0.5 \mathrm{mg} / \mathrm{kg} /$ day. All administrations were done after a starvation for $6 \mathrm{hr}$. Four days after the immunization, splenic antiSRBC PFC were assaved by the method of Jerne and Nordin (5). In the experiment of non-stressed mice, the procedures of immunization and administration were like those described above for the stressed mice.

Statistical analysis: All results are expressed as the arithmetic mean \pm S.D. of typical experiments in several independent studies. Statistical significance was analyzed by 
Student's t-test.

\section{Results}

In vitro effect on the antibody production: As shown in Fig. 2, TOK-8801 augmented the in vitro anti-SRBC PFC response of murine

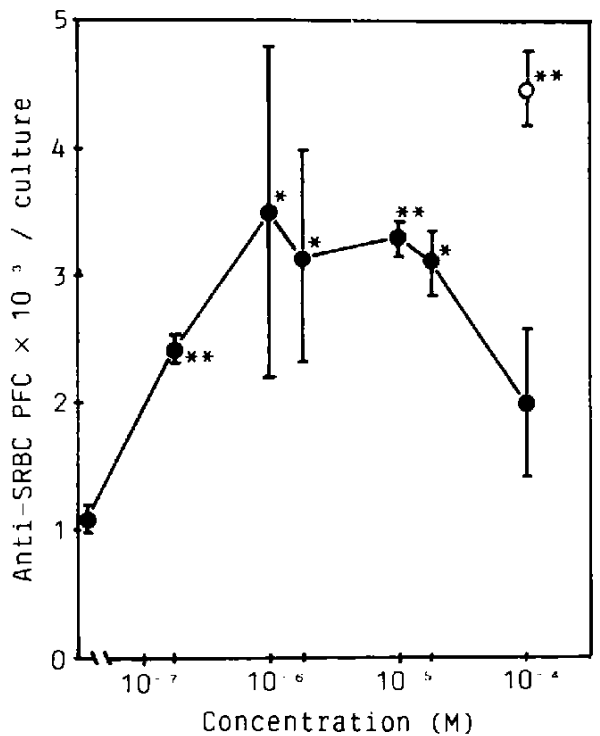

Fig. 2. Effect of TOK-8801 on the in vitro antiSRBC PFC response. Spleen cells were cultured with SRBC in the presence of varying concentrations of TOK-8801 $\left(2.5 \times 10^{-7}-1 \times 10^{-4} \mathrm{M}\right.$. O ) or LMS $\left(10^{-4} \mathrm{M}, \mathrm{O}\right)$ for 5 days. ${ }^{*}<0.05,{ }^{*} \mathrm{P}<0.01$. as compared with a control PFC response without compounds $(n=3)$. splenocytes in a bell-shaped manner. The stimulatory effect of this compound was observed at concentrations of $2.5 \times 10^{-7}-2.5 \times$ $10^{-5} \mathrm{M}$ and was diminished at $10^{-4} \mathrm{M}$. The cell-viability was not altered during the culture with this compound at any doses used in this experiment $\left(10^{-7}-10^{-4} \mathrm{M}\right)$. LMS barely exhibited a comparable potency at $10^{-4} \mathrm{M}$, and it was not stimulatory under $10^{-5} \mathrm{M}$ (data are not shown).

In order to characterize the stimulatory action of TOK-8801, it was determined whether this compound would augment the PFC response to $S R B C$ ( $T$ cell-dependent (TD) antigen) and TNP-LPS ( $T$ cell-independent (TI) antigen) of $T$ cell-depleted spleen cells. Both TOK-8801 and LMS elevated the number of PFC against SRBC and TNP-LPS of spleen cells treated with complement as a control, whereas such a stimulatory effect was not observed with $T$ cell-depleted spleen cells (Fig. 3). These results suggest that TOK8801 may augment the PFC production through acting on $\mathrm{T}$ cells.

In vitro effects on mitogen-induced proliferative responses: We studied the effect of TOK-8801 on the Con A- or L.PS-induced proliferative responses in spleen or thymus cells. As shown in Fig. 4, TOK-8801 enhanced the ${ }^{3} \mathrm{H}-\mathrm{TdR}$ uptake of these responses in a bell-shaped manner, and effective concentrations of this compound were $10^{-7}-10^{-5} \mathrm{M}$. while that of LMS was $10^{-4} \mathrm{M}$, as described
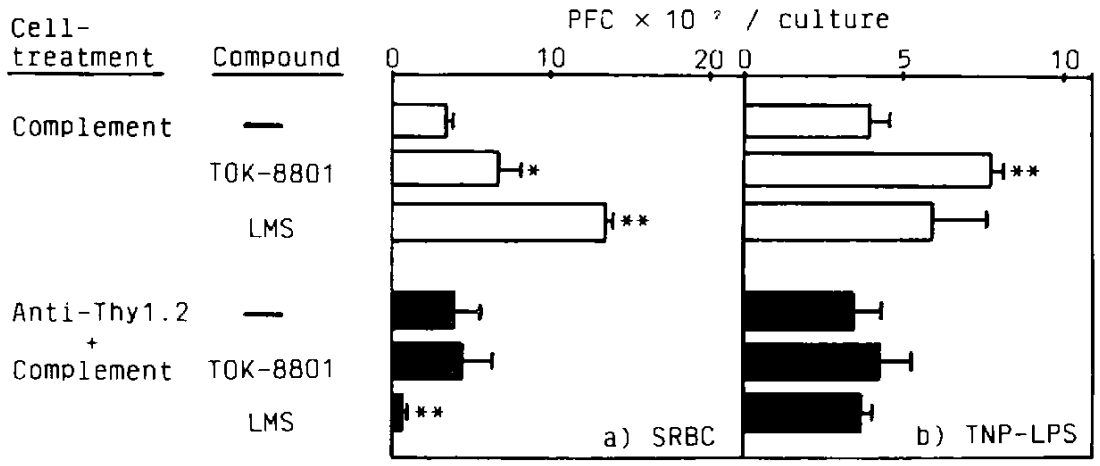

Fig. 3. T cell-dependent stimulation of the antibody production against SRBC and TNP-LPS by TOK8801. Spleen cells treated with complement only (open bar) or anti-Thyl. 2 antibody plus complement (closed bar) were cultured with SRBC (a) or TNP-LPS (b) in the presence of TOK-8801 (10-6 $\mathrm{M}$ ) or LMS $\left(10^{-4} \mathrm{M}\right)$ for 5 days. ${ }^{*} \mathrm{P}<0.05,{ }^{*} \mathrm{P}<0.01$, as compared with a control PFC response without compounds $(n=3)$. 
in the experiment of antibody response.

In vivo effect on the anti-SRBC PFC response in immunologically depressed mice: Restraint-stress mice were immunologically depressed, and their reduced anti-SRBC PFC production in spleen cells was mainly based on defects of helper T cells $(T h)(7,8)$. TOK8801 were orally administered to restraintstress mice at doses of $0.02,0.1$ and $0.5 \mathrm{mg} /$ $\mathrm{kg}$, and its effect on their depressed anti-
SRBC PFC response was studied. As shown in Fig. 5, the anti-SRBC PFC response per spleen, which was prominently lowered by restraint-stress $(P<0.05)$, was significantly restored by the administration of TOK- 8801 $(0.5 \mathrm{mg} / \mathrm{kg}, P<0.05)$. The number of total splenic lymphocytes in restraint-stress was decreased, but there were no significant changes in the number of total splenic lymphocytes by the treatment with this com-
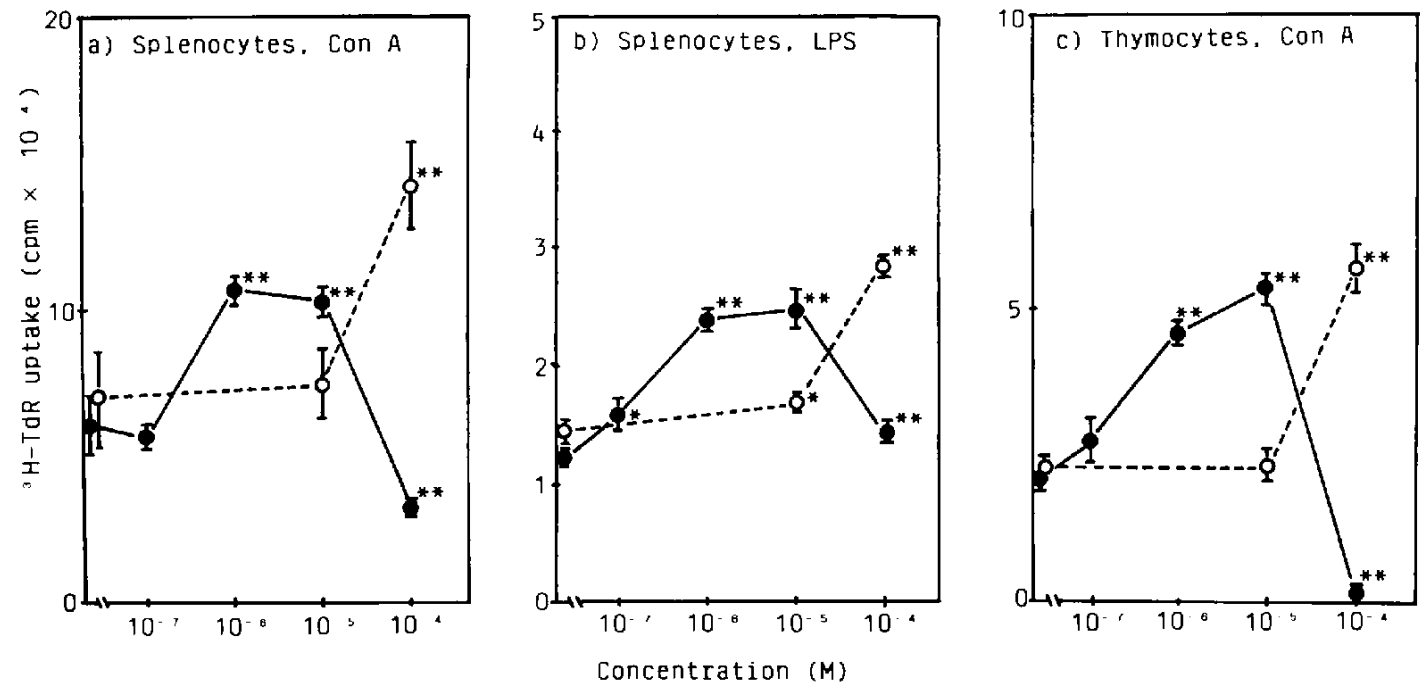

Fig. 4. Effect of TOK-8801 on the in vitro mitogen-induced proliferative responses. Spleen cells were cultured with Can A $(1 / \mu \mathrm{g} / \mathrm{ml}$, a) or LPS $(10 \mu \mathrm{g} / \mathrm{ml}, \mathrm{b})$ in the presence of varying concentrations of TOK8801 or LMS for 2 days and pulsed with ${ }^{3} \mathrm{H}-\mathrm{TdR}$ for an additional $18 \mathrm{hr}$. Thymus cells were cultured with Con $A(5 \mu \mathrm{g} / \mathrm{ml}, \mathrm{c})$ by the same procedure as described in the experiment of spleen cells. ${ }^{*} P<0.05$. ** $P<0.01$, as compared with a control ${ }^{3} \mathrm{H}-\mathrm{TdR}$ uptake without compounds $(n=3)$.

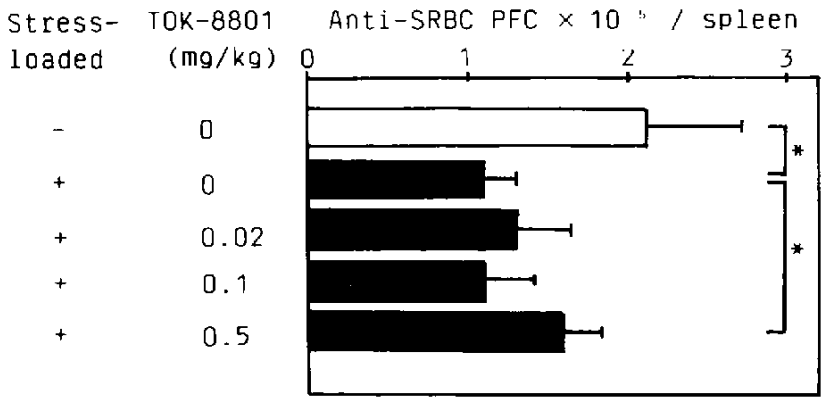

Fig. 5. Effect of the oral administration of TOK-8801 on the anti-SRBC PFC response in restraint-stress mice. Mice subjected to restraint-stress for 2 days were intraperitoneally immunized with SRBC and were orally given the indicated dose of TOK- 8801 for 3 days. Four days after the immunization, the anti-SRBC PFC response of spleen cells from treated mice were assayed. ${ }^{*} P<0.05(n=4)$, significantly different from the value of the stress control group without TOK-8801. 


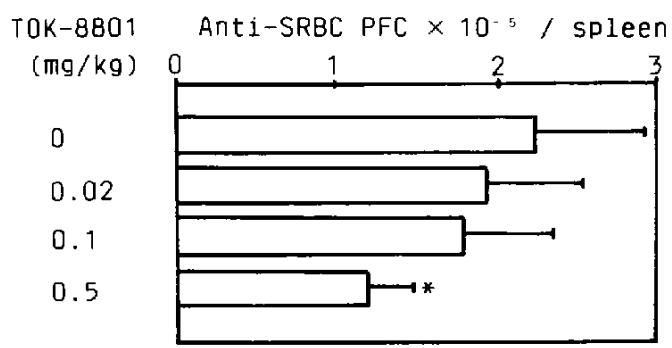

Fig. 6. Effect of the oral administration of TOK8801 on the anti-SRBC PFC response in nonstressed mice. The protocol of immunization and administration was described in Fig. 5. ${ }^{*} P<0.05$ $(n=4)$, significantly different from the value of the control group without TOK-8801.

pound (data not shown). The oral administration of LMS at a dose of $20 \mathrm{mg} / \mathrm{kg}$ also recovered the depressed anti-SRBC PFC production (data not shown).

On the contrary. when TOK-8801 was given to non-stressed mice, the number of anti-SRBC PFC per spleen was decreased (Fig. 6). A significant reduction of PFC production was seen at the dose of $0.5 \mathrm{mg} / \mathrm{kg}$ $(P<0.05)$. which was effective in the restraint-stress mice as demonstrated in Fig. 5. The number of total splenic lymphocytes was not significantly affected by the treatment with TOK-8801 (data not shown). LMS administration $(10 \mathrm{mg} / \mathrm{kg})$ decreased the PFC response in the non-stressed mice, although the difference was not significant (data not shown).

\section{Discussion}

TOK-8801 is a newly synthesized dihydroimidazothiazole carboxamide which is under development as an immunomodulator/ biological response modifier (BRM). In this study, the effect of TOK-8801 on the in vitro and in vivo antibody production was investigated compared with that of LMS, a synthetic immunostimulant (3). which has an imidazothiazole. In the in vitro experiments, TOK-8801 enhanced the anti-SRBC PFC response at the concentrations of $2.5 \times 10^{-7}$ $2.5 \times 10^{-5} \mathrm{M}$, which were concentrations 10-100 fold less than that of LMS $\left(10^{-4} \mathrm{M}\right)$. This stimulations of the PFC response to SRBC as well as TNP-LPS by both TOK- 8801 and LMS were eliminated after the removal of $T$ cells. The mechanism of antibody production is a complex process: that is, the proliferation and differentiation of resting $B$ cells is regulated by $T$ cells and $T$ cell-derived lymphokines. Therefore, TOK-8801 is suggested to augment the antibody production through acting on $T$ cells. SRBC belongs to the group of TD-antigens, while TNP-LPS belong to the group of $\mathrm{TI}$-antigens. However, it was reported that TNP-LPS behaves as a TD-antigen in some respects (9). Thus, it does not seem inconsistent that the potentiation of the TNP-L.PS response by TOK- 8801 may be $T$ cell-dependent.

In the in vivo experiment, this compound restored the depressed anti-SRBC PFC response in restraint-stress mice, which is mainly caused by the immunologically damaged Th function (7. 8). Komori et al. (10) confirmed that the depressed humoral immunity in the stressed mice was responsible for the Th dysfunction; that is, the restraintstress suppressed the PFC response to TDantigens, but not $\mathrm{TI}$-antigens, and reduced the proliferative response induced by Con $A$, but not LPS. They also reported that lobenzarit disodium (CCA), an anti-rheumatic drug (11). restored the depressed anti-SRBC PFC response caused by restraint-stress and that this effect of CCA may be based on the recovery of Th function. Therefore, it is conceivable that TOK-8801 restored the antiSRBC PFC response by the same mechanism as that of CCA. On the other hand, the administration of TOK-8801 to normal BDF mice reduced the antibody response, which was also seen in the study using a different strain of mice, $\mathrm{C} 3 \mathrm{H} / \mathrm{HeN}$ (K. Shibata et al., unpublished data). CCA has been demonstrated to stimulate Ts activities in some experimental systems (12-14). As TOK-8801 appears to have immunopharmacological features similar to CCA. TOK-8801 may lower the in vivo anti-SRBC PFC response through a mechanism involving the stimulation of Ts function in normal mice. In fact, our preliminary experiments suggest that TOK-8801 augments $T$ s activity in vivo and in vitro. More studies should be performed to determine if TOK-8801 really acts on regulatory $T$ cells such as Ts and Th. 
The in vitro proliferative response induced by Con A or LPS, which is a polyclonal activator of $T$ cells or $B$ cells, respectively, was enhanced by TOK-8801 and LMS. It appears that TOK-8801 as well as LMS may act indiscriminately in the proliferative response, in contrast to the PFC response, which is the early phase of the maturation process.

Further studies concentrating on the improvement of immunological disorders in autoimmune animals and the mode of action on $T$ cell activation by this compound are in progress.

\section{References}

1 Jaffé, I.A.: Rheumatoid arthritis with arteritis: Report of a case treated with penicillamine. Ann. Intern. Med. 61, 556-562 (1964)

2 Schuermans, $Y$.: Levamisole in rheumatoid arthritis. Lancet $i, 111$ (1975)

3 Symoens, J. and Rosenthal, M.: Levamisole in the modulation of the immune response: The current experimental and clinical state. $J$. Reticuloendothel. Soc. 21, 175-221 (1977)

4 Rittenberg, M.B. and Amkraut, A.A.: Immunogenicity of trinitrophenylhemocyanin: Production of primary and secondary anti-hapten precipitins. J. Immunol. 97, 421-430 (1966)

5 Jerne, N.K. and Nordin, A.A.: Plaque formation in agar by single antibody-producing cells. Science 140, 405 (1963)

6 Rittenberg, M.B. and Platt, K.L.: A. trinitrophenyl (TNP) plaque assay. Primary response of BALB/c mice to soluble and particulate immunogen. Proc. Soc. Exp. Bioi. Med. 132, 575581 (1969)

7 Okimura, T. and Yamamoto, I.: Stress and immune response; restraint-induced suppression of immune response in mice and its possible mechanisms. Proc. Japan. Soc. Immunol. 10, 251-252 (1980)

8 Okimura, T. and Yamamoto, 1.: Modulation of immune response by restraint-stress. II. Analysis of cells sensitive to restraint stress. Proc. Japan. Soc. Immunol. 12, 766-767 (1982)

9 Endres, R.O., Kushnir, E., Kappler, J.W., Marrack, $P$. and Kinsky, S.C.: A requirement for nonspecific $T$ cell factors in antibody responses to " $T$ cell independent" antigens. J. Immunol. 130, $781-784$ (1983)

10 Komori, T., Nakano, T. and Ohsugi, Y.: Alleviation of depressed immunity caused by restraintstress, by the immunomodulator, Iobenzarit disodium (disodium 4-chloro-2.2'-iminodibenzoate). Int. J. Immunopharmacol, 9, 433-441 (1987)

11 Shiokawa, Y., Horiuchi, Y., Mizushima, Y., Kageyama, T., Shichikawa, K., Ohfuji, T., Honma, M., Yoshizawa, H., Abe C. and Ogawa, N.: A multicenter double-blind controlled study of lobenzarit, a novel immunomodulator. in rheumatoid arthritis. J. Rheumatol. 11, 615-623 (1984)

12 Nakano, T., Yamashita, Y., Ohsugi, Y., Sugawara, Y., Hata, S. and Takagaki, Y.: The effect of CCA (lobenzarit disodium) on the suppressor T cell function and the production of autoantibodies in New Zealand Black and New Zealand White $F_{1}$ mice. Immunopharmacology 5, 293-302 (1982)

13 Yamamoto, I., Ohmori, H. and Sasano, M.: CCA: An immunopharmacological profile in vivo and in vitro. Drugs Exp. Res. VIII, 5-10 (1982)

14 Yamamoto, I., Ohmori, $\mathrm{H}$. and Sasano, M.: Effect of $\mathrm{N}$-(2-carboxyphenyl)-4-chloroanthranilic acid disodium salt (CCA) on the induction of helper and suppressor $T$ cells in vitro and in vivo. Japan. J. Pharmacol. 33,859866 (1983) 